\title{
Artigo
}

\section{Além de anjos caídos e estrelas em ascensão: as agências de classificação de risco de crédito e o sistema financeiro global}

Beyond fallen angels and rising stars: credit rating agencies and the global financial system

\author{
Diego Santos Vieira de Jesus \\ Professor do Instituto de Relações Internacionais da PUC-Rio \\ (IRI / PUC-Rio) e da Escola Superior de Propaganda e Marketing \\ do Rio de Janeiro (ESPM-RJ). \\ E-mail: <dsvj@puc-rio.br>.
}

Resumo: Os objetivos são explicar a posição influente das agências de classificação de risco de crédito no sistema financeiro global contemporâneo e examinar como tais agências interferem na dinâmica das crises financeiras internacionais desde a década de 1990. O argumento central aponta que as agências de classificação de risco de crédito definem padrões de fiabilidade creditícia baseadas no conhecimento de que dispõem e oferecem regras organizacionais nas quais definem estruturas e práticas conducentes a uma maior fiabilidade creditícia e com relação às quais o compromisso é voluntário. Para atores que contraem empréstimos, um rebaixamento na avaliação de risco de crédito por uma agência num contexto de uma crise financeira internacional pode ter efeitos negativos no seu acesso ao crédito e no custo de se contraírem empréstimos. A fim de evitar rebaixamentos nas avaliações, Estados podem adotar políticas que atendam às preocupações de curto prazo dos investidores mesmo quando elas entram em conflito com as necessidades de desenvolvimento de longo prazo. Os rebaixamentos nas avaliações de risco de títulos soberanos podem ter efeitos significativos de transbordamento da crise para Estados e mercados financeiros, o que amplia a pressão por maior regulação das agências em termos de melhorias na sua governança interna, da transparência acerca dos procedimentos de avaliação e do comprometimento com códigos internacionais de conduta.

Palavras-chave: Agências de Classificação de Risco de Crédito; Sistema Financeiro Global; Crise Financeira Internacional; Regulação Financeira.

\footnotetext{
Abstract: The objectives are to explain the influential position of credit rating agencies at the contemporary global financial system and examine how such agencies interfere with the dynamics of international financial crises since the 1990s. The central argument suggests that credit rating agencies define creditworthiness standards based on the knowledge they have and offer organizational rules which define the structures and
} 
practices leading to greater creditworthiness and with which the commitment is voluntary. For actors who take loans, a rating downgrade by an agency in the context of an international financial crisis could have negative impacts on their access to credit and the cost of holding loans. To avoid downgrades in the ratings, states can adopt policies that address the short-term concerns of investors even when they conflict with the needs of longterm development. The downgrades in the ratings of sovereign bonds may have significant spillover effects of the crisis for states and financial markets, which increases the pressure for greater regulation of the agencies in terms of improvements of their internal governance, the transparency of the rating procedures and the commitment with international codes of conduct.

Keywords: Credit Rating Agencies; Global Financial System; International Financial Crisis; Financial Regulation

As principais agências de classificação de risco de crédito do mundo - a Standard \& Poor's (S\&P) Rating Services, a Moody's Investors Services e a Fitch Ratings - são alvos de inúmeras críticas em especial desde o início da crise financeira nos EUA em 2008. Elas foram criticadas pelas suas avaliações inicialmente favoráveis de instituições financeiras insolventes como o banco de investimento e provedor de outros serviços financeiros Lehman Brothers, bem como dos títulos relacionados a hipotecas de alto risco que contribuíram para o colapso do mercado imobiliário nos EUA. Desde 2010, tais agências focaram na dívida soberana dos EUA e de Estados da União Europeia. Isso resultou em um rebaixamento da classificação dos EUA no início de agosto de 2011, dando início a uma volatilidade no mercado que não era vista desde dezembro de 2008. Tais agências também rebaixaram as classificações de Grécia, Portugal e Irlanda, uma ação que muitos membros da União Europeia afirmam ter acelerado uma crise da dívida soberana na Zona do Euro. Em janeiro de 2012, em meio à instabilidade contínua na Zona do Euro, a S\&P rebaixou a classificação de nove Estados da Zona do Euro, como a França e a Áustria. Tanto os EUA como a União Europeia tomaram medidas para regular as três principais agências e garantir mais transparência e competitividade (ALESSI et al., 2013).

Tais agências desempenham um papel importante nos mercados financeiros, uma vez que produzem avaliações de risco de crédito para mutuários soberanos e do setor privado em todo o mundo. Os mercados financeiros confiam nas agências também pelo fato de constantemente atualizarem as avaliações de risco de crédito que produziram para os emissores de títulos. Essas avaliações oferecem aos mercados financeiros uma estimativa da probabilidade dos mutuários de não cumprirem as obrigações especificadas em suas emissões de títulos de dívida. Quanto mais elevada a classificação, 
menor é tal probabilidade. Além de afetarem os custos para que os emissores possam contrair empréstimos, as avaliações determinam a extensão dos investidores potenciais. Os estatutos e as regulações proíbem investidores institucionais de investir em ativos que tenham classificações abaixo de certo nível. Quando um emissor tem sua classificação rebaixada, a extensão de investidores potenciais significativamente diminui (FERRI et al., 1999, p. 335-336). A lógica subjacente à existência das agências é a solução de problemas de assimetria de informação entre credores e mutuários com relação à fiabilidade creditícia dos últimos. Além disso, as avaliações determinam a elegibilidade da dívida e de outros instrumentos financeiros para os portfólios de certos investidores institucionais devido às regulações que restringem a compra de títulos especulativos (ELKHOURY, 2009, p. 165). Nas áreas de Ciência Política e de Relações Internacionais, é possível ver as agências de classificação de risco de crédito como instituições que fazem mais do que oferecer informação ao mercado. As atividades de avaliação do risco de crédito pelas agências não são externas à relação entre mutuários e credores. Com sua informação sobre o risco de crédito, as agências transformam as incertezas das relações de crédito em riscos calculáveis. Assim, elas efetivamente delineiam as expectativas mútuas entre os credores e os mutuários. Como não há uma alternativa de peso às avaliações nas relações de crédito, amplia-se o poder de sanção que a possibilidade de uma análise de risco de crédito negativa - um rebaixamento - confere às agências. Nesse sentido, as agências têm uma autoridade epistêmica que traz uma dimensão política, uma vez que justifica os mercados financeiros como meios neutros e eficientes para a alocação de recursos, embora favoreçam uma elite financeira e desfavoreçam a redistribuição (KERWER, 2002, p. 296). Porém, é possível argumentar que tais agências podem ter papéis que transcendam sua autoridade epistêmica.

Os objetivos deste artigo são explicar a posição influente das agências de classificação de risco de crédito no sistema financeiro global contemporâneo e examinar como tais agências interferem na dinâmica das crises financeiras internacionais desde a década de 1990. O argumento central aponta que, mais do que serem provedores de informação ou justificarem a neutralidade dos mercados financeiros para a alocação de recursos favorecendo elites, as agências de classificação de risco de crédito definem padrões de fiabilidade creditícia baseadas no conhecimento de que dispõem e oferecem regras organizacionais nas quais definem estruturas e práticas conducentes a uma 
maior fiabilidade creditícia e com relação às quais o compromisso é voluntário. Para atores que contraem empréstimos, um rebaixamento na avaliação de risco de crédito por uma agência num contexto de uma crise financeira internacional pode ter efeitos negativos no seu acesso ao crédito e no custo de se contraírem empréstimos. Assim, no caso de Estados em contexto da crise, é razoável assumir que políticas ortodoxas que foquem na redução da inflação e dos déficits orçamentais sejam favorecidas. A fim de evitar rebaixamentos nas avaliações, Estados podem adotar políticas que atendam às preocupações de curto prazo dos investidores, mesmo quando elas entram em conflito com as necessidades de desenvolvimento de longo prazo. Os rebaixamentos nas avaliações de títulos soberanos podem ter efeitos significativos de transbordamento da crise para Estados e mercados financeiros, o que amplia a pressão por maior regulação das agências em termos de melhorias na sua governança interna, da transparência acerca dos procedimentos de avaliação e do comprometimento com códigos internacionais de conduta. A seguir, apresentarei a história e as principais características e funções das agências de classificação de risco de crédito. No item seguinte, explorarei as principais críticas feitas a tais agências e, posteriormente, a forma como essas instituições interferem na dinâmica de crises internacionais financeiras. Antes de tecer as considerações finais, apresentarei o debate acerca da regulação das agências.

\section{A história e as principais características e funções das agências}

Alguns dos primeiros títulos emitidos datam do início do século XVII, quando a Companhia das Índias Orientais emitiu títulos para financiar suas operações no Sudeste Asiático. Posteriormente, os governos holandês e inglês emitiram títulos soberanos. Esses títulos eram garantidos pelo poder dos seus governos e tinham risco insignificante de inadimplência. Foi somente na segunda metade do século XIX que empresas privadas procuraram mobilizar recursos para grandes projetos como ferrovias e estaleiros por meio da emissão de títulos, o que trouxe a necessidade de avaliar o risco de inadimplência. A história do setor de avaliação de risco de crédito coincide com a evolução das agências de classificação de risco de crédito nos EUA. Tais agências cobriam uma lacuna de informação entre emissores de títulos e investidores oferecendo avaliações da fiabilidade creditícia de títulos emitidos por várias entidades, incluindo governos e 
corporações. As avaliações não se propunham a oferecer uma auditoria, uma validação das operações das empresas ou uma recomendação para se investir em um título avaliado. Nos EUA, as avaliações são consideradas "opiniões" e assim são protegidas de responsabilidade jurídica como discursos livres protegidos pela Primeira Emenda à Constituição dos EUA. Um sistema informal de avaliação de títulos data de meados do século XIX. Avaliações posteriores foram utilizadas no início do século XX quando John Moody publicou análises da fiabilidade creditícia de companhias do setor ferroviário. Essas avaliações não eram baseadas em análises estatísticas complicadas e sintetizavam informações sobre títulos que seriam difíceis para que investidores analisassem (RANDHAWA, 2011, p. 2).

As avaliações assumiram importância ainda maior na década de 1930 depois da Grande Depressão, quando, a fim de proteger os bancos, a Reserva Federal nos EUA exigiu que os bancos somente investissem em títulos que tivessem o "nível de investimento". Reguladores de fundos de pensão e corretoras seguiram orientações semelhantes, estipulando que as instituições financeiras sob sua supervisão aderissem a orientações de que seus investimentos em títulos preenchessem um limiar de avaliação em "nível de investimento". As avaliações eram de importância vital, pois auxiliavam na determinação da elegibilidade de títulos que os bancos poderiam adquirir a fim de preencher os requisitos de adequação de capital. Numa tentativa de criar mais regulações para as agências, a Comissão de Títulos e Câmbio dos EUA estipulou normas para que as instituições de avaliação fossem classificadas como "organizações de classificações estatísticas nacionalmente reconhecidas". As instituições financeiras poderiam investir em títulos avaliados por essas organizações. Gradativamente, tais avaliações foram incorporadas em leis federais e estaduais e contratos privados. O Acordo de Capital da Basileia II de 2004 também explicitou fatores nas avaliações para a determinação dos requisitos de capital por parte dos bancos. As agências de classificação de risco de crédito gradativamente se transformaram de intermediários de informação para provedores de licenças regulatórias de facto (RANDHAWA, 2011, p. 3).

As agências de classificação de risco de crédito avaliam títulos de dívida emitidos por governos e empresas e também títulos financeiros estruturados. Uma avaliação de crédito é uma opinião da agência sobre a fiabilidade creditícia de um devedor com respeito a um título de dívida específico ou outra obrigação financeira. Dentre 
as funções da avaliação de risco de crédito, cabe destacar a solução da assimetria de informação entre emissores e investidores ao medirem o risco de crédito do emissor objetivamente, a ampliação da eficiência do funcionamento dos mercados financeiros e a oferta de meios de comparação para todas as questões relacionadas ao risco de crédito, bem como de uma escala de avaliação global no auxílio à construção de um portfólio (BAYAR, 2014, p. 49-50). As agências devem oferecer aos investidores globais uma análise do risco associado aos títulos de dívida. Esses títulos incluem títulos da dívida de governos, títulos corporativos, certificados de depósito, ações preferenciais e títulos colateralizados. O risco de investir nesses títulos é determinado pela probabilidade de que o emissor da dívida - seja uma empresa, uma entidade bancária, um Estado soberano ou um governo local - não consiga realizar o pagamento dos juros sobre a dívida. As avaliações emitidas pelas grandes agências têm inúmeras implicações para investidores e mercados globais (ALESSI et al., 2013). Em 2009, as três agências principais - S\&P, Moody's e Fitch - eram responsáveis pela maior parte das avaliações de finanças estruturadas. Existem algumas agências menores que estão ativas nos EUA, mas algumas delas são ativas primariamente em nichos específicos, e nenhuma delas têm a parcela total do mercado que seja comparável às principais agências' (HUNT, 2009, p. 5-6). Existe também uma grande disparidade em termos de tamanho e escopos geográfico e setorial de cobertura pelas agências, além de diferenças nas suas metodologias e definições de risco de inadimplência. Tais aspectos dificultam a comparação entre elas. Uma avaliação de risco de crédito comprime uma grande quantidade de informação que precisa ser conhecida acerca da fiabilidade creditícia do emissor de títulos e de outros instrumentos financeiros. As agências destacam que suas avaliações constituem opiniões, não sendo recomendações para vender, comprar ou manter um título e não falam sobre a adequabilidade de um investimento para um investidor. As avaliações têm um impacto sobre os emissores por meio de vários esquemas regulatórios e da

BOLTON et al. (2012, p. 86) argumentam que a concorrência entre as agências pode reduzir a eficiência de mercado uma vez que facilita a compra de avaliações por emissores. Segundo os autores, a eficiência pode ser maior sob o monopólio de uma agência do que por um duopólio, apesar do potencial para a ampliação da informatividade de duas avaliações. As agências também se mostram mais propensas a inflar as avaliações durante os períodos em que há uma maior clientela de investidores no mercado que consideram as avaliações de forma valorosa e os riscos de fracasso que podem prejudicar a reputação da agência são menores. 
determinação de condições e custos para que se tenha acesso aos mercados de dívidas (ELKHOURY, 2009, p. 166-167).

As agências de classificação de risco de crédito definem padrões de fiabilidade creditícia baseadas no conhecimento de que dispõem e oferecem regras organizacionais nas quais definem estruturas e práticas conducentes a uma maior fiabilidade creditícia e com relação às quais o compromisso é voluntário. Mesmo havendo outras fontes de informação, a posição influente das agências resulta não somente de sua importância na orientação de atores diante da complexidade do mercado. Os padrões de fiabilidade creditícia desenvolvidos pelas agências foram adotados na regulação do mercado financeiro, tendo se tornado mandatório observar tais padrões em diversas instâncias e se excluindo o uso de visões alternativas sobre fiabilidade creditícia como possíveis substitutos. A expansão do uso das avaliações de risco de crédito tem a ver não somente com os esforços de reguladores dos EUA de exportar os padrões de fiabilidade creditícia, mas com o desejo de investidores de acessar o mercado de capital norte-americano e a emulação dos reguladores ao redor do mundo quanto ao uso desses padrões nas suas regulações (KERWER, 2002, p. 297-310).

Ao incorporarem as avaliações de crédito nos seus requisitos, os reguladores efetivamente ampliaram as funções regulatórias das agências de classificação de risco de crédito, tornaram as avaliações de risco de crédito essenciais para emissores e fizeram delas o pilar das regulações em diversos setores financeiros. Como aponta White (2010a, p. 214), as regras regulatórias implicavam que os julgamentos das agências assumissem importância fundamental nos mercados de títulos. Bancos e muitas outras instituições financeiras deveriam ter atenção às avaliações em vez de seguirem suas próprias avaliações dos riscos dos títulos. Como essas instituições financeiras reguladas eram participantes importantes no mercado de títulos, outros jogadores no mercado - tanto compradores como vendedores - precisavam ter uma atenção particular aos pronunciamentos dos avaliadores desses títulos.

Nesse sentido, as agências de classificação de risco de crédito desempenham o papel fundamental de "leões de chácara" do mercado de capitais, apesar de sua aparente falta de obrigação e sua relutância em assumir tamanha responsabilidade. Uma avaliação de risco de crédito acabou se tornando uma precondição para a oferta de dívidas em virtualmente todos os Estados que tenham um mercado de dívidas. O setor 
de avaliação de risco de crédito é atualmente dominado por grandes empresas devido às elevadas barreiras à entrada de novas instituições, que derivam do capital reputacional e da extensão da cobertura construída pelas agências bem-sucedidas ao longo do tempo. As agências enfrentam a pressão de competirem para manterem sua parcela do mercado e seus lucros. As agências de classificação de risco de crédito também tiveram um papel central no desenvolvimento do mercado de produtos estruturados. Como muitos investidores institucionais e mesmo bancos viam a dívida com a mesma avaliação de crédito como fungível, mesmo os instrumentos de dívida mais complexos, inovadores ou opacos poderiam ser vendidos se recebessem uma avaliação favorável ao investimento. A menor transparência e a maior complexidade nesse mercado garantiu uma confiança pesada pelos seus participantes nas agências de classificação de risco de crédito. Enquanto a fácil disponibilidade de avaliações alimenta o crescimento desse mercado, os rebaixamentos subsequentes nas avaliações aceleram o seu colapso (KATZ et al., 2009, p. 2-3).

Especialistas que aderiram à escola de pensamento do "capital reputacional" geralmente defendem que a função das agências de classificação de risco de crédito é fazer análises de alta qualidade da fiabilidade creditícia dos emissores e que o valor das atividades de uma agência deriva de sua reputação ao disponibilizar avaliações de alta qualidade. Tais especialistas acreditam que a disciplina do mercado, na forma de medo da perda de reputação, oferecerá ou deverá oferecer os incentivos para avaliações de alta qualidade. Eles creem que um mau desempenho será dissuadido pela perspectiva de perda de reputação. É possível identificar aspectos do mercado de avaliação de risco de crédito que podem levar as agências a terem desempenhos piores do que poderiam ter. Dentre eles, cabe citar a falta de concorrência percebida, a falta de transparência, os conflitos de interesse e a regulação dependente das classificações, situação na qual as avaliações das agências são incorporadas na regulação financeira, nos contratos privados e nas orientações dos investidores, criando uma fonte de demanda de avaliações que não está diretamente ligada à sua qualidade. Opiniões sobre a importância desses aspectos variam, mas elas podem, separadamente ou em combinação, levar o mecanismo reputacional a um desempenho ruim. Algumas propostas regulatórias tiveram por objetivo solucionar esses problemas e eram baseadas na ideia de que o mecanismo 
reputacional pode produzir bons resultados se alguns ou todos esses problemas fossem resolvidos (HUNT, 2009, p. 17-18).

Entretanto, segundo Hunt (2009, p. 45-53), os reguladores ignoraram a possibilidade de que as restrições reputacionais sobre a baixa qualidade fossem fundamentalmente insuficientes em algumas situações, como na avaliação de novos produtos financeiros. Para o autor, a reputação pode gerar incentivos insuficientes para avaliações de alta qualidade de produtos novos. As agências não enfrentam transbordamentos negativos ao atribuírem avaliações de qualidade reduzida em novos segmentos. Mesmo se as agências enfrentarem um risco de transbordamento reputacional, a evidência recente sugere que as avaliações de novos produtos foram lucrativas o suficiente para estimulá-las a arriscar e que, se a inovação financeira continua sendo importante, as agências continuarão a se estimular. Ademais, a agência sabe se é capaz de avaliar novos instrumentos com alta qualidade. A dissuasão da disponibilização de avaliações que a agência pensa que sejam de baixa qualidade reduzirá a emissão de avaliações de baixa qualidade, embora ao custo de dissuadir a emissão de avaliações de alta qualidade também. Finalmente, é importante destacar que a agência nem sempre percebe que esperar para entrar em um novo segmento resultará em lucros maiores do que entrar imediatamente.

A mudança do Estado como autoridade pública que ocupava a posição de único agente a legitimamente formular decisões coletivamente vinculantes envolve uma mudança na natureza das regras usadas. As agências de classificação de risco de crédito - sendo autoridades privadas - estabeleceram padrões importantes para o risco de crédito ao avaliarem um amplo conjunto de mutuários diferentes de acordo com uma mesma escala e publicando análises de risco de crédito usadas para a formulação de decisões de investimento no mercado. Além disso, as agências foram utilizadas para a regulação do mercado financeiro, por exemplo, ao se limitarem as atividades de investimento dos bancos aos instrumentos de baixo risco de crédito. Tais funções tornaram-se gradativamente importantes conforme as agências se expandiram geograficamente ao redor do planeta. Como consequência, a avaliação negativa de uma agência sobre fiabilidade creditícia pode significativamente ampliar o custo de se contraírem empréstimos para empresas e Estados soberanos. Apesar da severidade potencial dos efeitos adversos de um rebaixamento, as agências frequentemente ignoraram as queixas sobre 
estimativas incorretas de risco de crédito. Como consequência, apesar do fato de que as agências se tornaram crescentemente influentes nos mercados financeiros de todo o mundo, é muito difícil fazer com que prestem conta das suas ações. Tais agências raramente têm de justificar suas decisões ou oferecer compensações a outros atores por consequências adversas de seus erros (KERWER, 2002, p. 294-295). Para Kerwer (2002, p. 295), o papel das agências no enforcement regulatório - e não seu papel central nos mercados financeiros - é a chave do poder dessas instituições. A autoridade pública tem um papel crucial na constituição da autoridade privada das agências.

\section{As críticas às agências}

A maior crítica feita a tais agências está centrada no pagamento pelo emissor, ou seja, um emissor de título paga às agências de classificação de risco de crédito a avaliação inicial e as avaliações contínuas de um título. Os investidores têm acesso a essas avaliações sem pagar. Muitas agências mudaram para esse modelo na década de 1970, depois de anos de um modelo que requeria que grandes instituições investindo em títulos pagassem as avaliações. Essa mudança ocorreu em parte porque os avaliadores perceberam que os emissores estavam mais determinados a pagar esses serviços do que os investidores, uma vez que os emissores precisavam de avaliações a fim de vender seus títulos para instituições financeiras reguladas (ALESSI et al., 2013). Entretanto, a mudança para um modelo baseado no pagamento pelo emissor abriu a possibilidade para conflitos de interesse: uma agência pode atribuir uma nota de crédito mais elevada a fim de agradar um emissor e impedir que ele busque a avaliação por outra agência. Entretanto, a preocupação das agências com sua reputação de longo prazo aparentemente permitiu administrar esses conflitos ao longo das primeiras décadas do novo modelo (WHITE, 2010a, p. 215).

Uma situação de interdependência mútua formou-se entre as agências, os emissores de títulos e os investidores. As agências tinham incentivos para elevar as notas de crédito para não perderem clientes e também atraírem mais clientes. Ademais, as agências enfrentavam pouco ou nenhum risco de perda por conta de avaliações imprecisas, e os emissores de títulos precisavam de avaliações de crédito elevadas a fim de criarem e venderem instrumentos financeiros complexos. Como investidores institucionais e 
individuais teriam dificuldades de fazer avaliações sobre o risco de novos ativos complexos, eles confiaram nas classificações de risco de crédito das agências sem muito questionamento às atividades das agências. As agências ofereciam também serviços de avaliação e de consultoria simultaneamente antes das crises recentes. Assim, conflitos de interesse surgiam quando a agência oferecia a consultoria ou outros serviços semelhantes para os emissores que avaliavam. As agências primeiramente apontavam aos emissores o que eles deveriam fazer e então avaliavam tais emissores. Ademais, a avaliação de risco de crédito é um processo bilateral em que as agências determinam classificações baseadas nas informações oferecidas voluntariamente pelos emissores. Contudo, tais agências não têm o poder de garantir e examinar a informação e não podem solicitar informações adicionais à força. Há, portanto, o risco de que o emissor possa manipular a informação (BAYAR, 2014, p. 50).

As críticas às agências se acentuaram com sua atuação diante das crises mexicana e asiática da década de 1990. O fracasso das agências em prever essas crises ocorreu devido ao fato de que as obrigações financeiras contingentes e as considerações de liquidez internacional não foram levadas em consideração por tais instituições. No que diz respeito à crise asiática, muitas delas como a Moody's reconheceram que tinham sido confrontadas com um novo conjunto de circunstâncias que requeria uma mudança de paradigma em aspectos como uma maior ênfase analítica nos riscos de dívidas de curto prazo para Estados outrora dignos de crédito e na identidade e na fiabilidade creditícia de mutuários de curto prazo de um Estado; uma maior apreciação dos riscos colocados por um fraco sistema bancário; uma maior atenção à identidade e ao comportamento provável de credores estrangeiros de curto prazo e uma sensibilidade ampliada ao risco de que uma crise financeira em um Estado possa levar a efeitos de contágio para outros Estados (ELKHOURY, 2009, p. 174). Ao fracassarem na previsão da emergência da crise asiática, as agências se tornaram excessivamente conservadoras. Elas rebaixaram as avaliações de Estados asiáticos em crise mais do que a crise nos aspectos econômicos fundamentais justificaria. Isso exacerbou o custo desses Estados de contraírem empréstimos no exterior e levou a oferta de capital internacional a tais Estados a se evaporar. As classificações mais baixas do que as merecidas contribuíram para ampliar a crise asiática. As agências buscaram se recuperar dos prejuízos que tais erros causaram para elas e reconstruir sua própria reputação. Ao justificarem seus erros, tais agências defenderam 
que a crise asiática teve aspectos diferentes em relação a crises anteriores, uma vez que, no Leste da Ásia, as finanças públicas estavam em ordem e havia problemas no setor privado que derem início a uma crise para soberanos. Os aspectos novos da crise asiática, segundo as agências, impossibilitaram a sua previsão por instituições que baseavam suas avaliações em modelos estatísticos, sem ainda levarem em conta, por exemplo, as vulnerabilidades do setor privado (FERRI et al., 1999, p. 335-336).

Durante a crise financeira global iniciada em 2008, as agências de classificação de risco de crédito foram acusadas de criar modelos complexos para calcular a probabilidade de inadimplência para hipotecas individuais e os produtos estruturados que essas hipotecas compunham. As agências avaliavam bem muitos desses produtos durante os anos de crescimento acelerado do mercado imobiliário para somente rebaixarem a classificação quando tal mercado entrou em colapso. Críticos apontaram que as agências fracassaram no seu julgamento acerca da probabilidade de declínio nos preços de moradias e seu efeito sobre a inadimplência. Essas avaliações infladas também não levaram em conta o maior risco sistêmico associado ao rebaixamento da classificação de produtos estruturados, em oposição a títulos mais simples como os soberanos e os corporativos. As três grandes agências defendiam que as decisões de classificação eram tomadas por comitês de avaliação, não analistas individuais, e que os analistas não eram compensados baseados nas suas avaliações (ALESSI et al., 2013).

O fracasso das agências de classificação de risco de crédito de preverem corretamente a inadimplência das dívidas em produtos estruturados levou muitos comentadores a se perguntarem se os sistemas de avaliação estavam todos falhos. Alguns sugeriam que a falha refletia uma diferença básica na qualidade dos dados usados para desenvolver as avaliações. As avaliações da dívida estruturada são muitas vezes baseadas em informações não públicas e não auditadas oferecidas pelo emissor. Ao passo que os fracassos na avaliação de produtos estruturados tornaram-se o foco da crítica ao desempenho das agências de avaliação de risco de crédito, o problema não é novo. Elas são há muito tempo acusadas de serem lentas para reagir a eventos do mercado. Alguns exemplos são seu fracasso em prever problemas financeiros severos de emissores soberanos - como nas crises das dívidas latino-americanas e no colapso da Argentina em 2001 - e de empresas estabelecidas, como a Enron, a WorldCom e a Parmalat. A literatura empírica destaca que as avaliações têm pouco valor informacional e que, 
embora as avaliações possam representar o risco de crédito relativo relativamente bem, elas podem ser menos confiáveis como indicadores de risco absoluto. Demoras no rebaixamento de uma classificação podem ser explicadas por fatores que não sejam a incompetência. Um rebaixamento pode ter um efeito adverso para um emissor soberano ou corporativo avaliado, de forma que pode desestabilizar o emissor ou o mercado (KATZ et al., 2009, p. 4-5).

\section{Como as agências interferem na dinâmica das crises internacionais}

O crescimento dos mercados financeiros internacionais ao longo dos últimos vinte anos seria impensável sem as agências de classificação de risco de crédito. Por causa da disponibilidade de indicadores claros e internacionalmente aceitos de risco de crédito, os investidores mostraram-se determinados a investir em títulos internacionais - fossem corporativos ou soberanos - cuja qualidade de crédito eles não poderiam avaliar por eles mesmos. As agências trabalharam por décadas na elaboração de um sistema compreensível e simples que permitiria a qualquer investidor investir em títulos internacionais com os quais não eram familiares. Esse sistema mostrou-se confiável e permitiu aos investidores diversificar seus portfólios. Nos mercados de produtos estruturados, o papel das agências foi muito além da eliminação da assimetria de informação. Os mercados de produtos estruturados não poderiam ter se desenvolvido sem a garantia de qualidade oferecida pelas agências para os investidores sobre produtos financeiros inerentemente complexos. Entretanto, as avaliações para o crédito estruturado acabaram sendo muito menos robustas na previsão de desenvolvimentos futuros do que as avaliações para títulos mais tradicionais. Nos últimos anos, as mudanças nas avaliações do crédito estruturado foram mais voláteis e pesaram muito mais na direção de rebaixamentos. A instabilidade resultante minou a confiança na estabilidade futura das avaliações de crédito. Nesse contexto, pressões para a maior regulação das agências cresceram, em particular porque elas poderiam ser acusadas de terem cometido erros sérios nas suas avaliações: a subestima substancial do risco inerente a produtos financeiros estruturados ocorrera parcialmente devido a limitações metodológicas das agências, além da utilização de dados históricos inadequados e do fato de as agências não terem 
levado suficientemente em conta a deterioração dos padrões de empréstimo. Críticos apontavam a necessidade de melhorias na governança interna, a transparência acerca dos procedimentos de avaliação e o comprometimento das agências com códigos internacionais de conduta (UTZIG, 2010, p. 1-2).

As agências de classificação de risco de crédito, em seus papéis de agregadoras e processadoras de informação, podem reduzir os custos de capital de uma firma ao certificarem seu valor em um mercado, assim solucionando ou reduzindo as assimetrias informacionais entre compradores e emissores. Para mutuários soberanos, há evidência de uma clara correlação entre os spreads (diferenciais de rendimento) de títulos e as classificações. Quanto mais baixas são as classificações, maior é o spread. Existem outros benefícios indiretos de avaliações, em especial para economias emergentes, como o estímulo ao investimento estrangeiro direto, a promoção de mercados de capital locais mais dinâmicos e o aumento da transparência financeira do setor público (ELKHOURY, 2009, p. 172-173). Durante a década de 1990, os mercados de títulos globais se tornaram uma fonte importante de financiamento para muitas economias emergentes. Por conta disso, agências eram vistas por muitos participantes do mercado como tendo um impacto forte sobre os custos do financiamento e a determinação de grandes investidores institucionais de adquirirem certos tipos de instrumentos. Além disso, alguns investidores institucionais são constrangidos a adquirir títulos que foram classificados pelas agências com o "nível de investimento" como resultado de regulações oficiais ou de práticas internas de gestão de risco. As avaliações de risco do crédito soberano em geral serviram como um teto para as avaliações do setor privado de qualquer Estado, o que amplia a influência das agências para além dos títulos governamentais (KRÄUSSL, 2003, p. 2).

Como outras avaliações de crédito, as avaliações de crédito soberano são análises da probabilidade de que um mutuário seja inadimplente com suas obrigações. As agências interpretam suas avaliações como indicações do risco relativo de que os emissores da dívida não terão a habilidade e a determinação para realizar pagamentos completos e no prazo previsto para instrumentos específicos avaliados. Embora as avaliações de risco de crédito sejam influenciadas por fatores cíclicos, os funcionários das agências indicam que as avaliações tentam olhar através de ciclos econômicos e políticos. Assim, uma recessão ou a redução da liquidez global não deveriam por elas 
mesmas ser a razão para o rebaixamento da avaliação de um título soberano. As principais agências argumentam que não consideram que suas avaliações ofereçam uma previsão de tempo de inadimplência ou uma indicação do nível absoluto de risco associado a uma obrigação específica. Elas ainda declaram que uma avaliação não é uma recomendação para adquirir, vender ou manter um título financeiro nem fala sobre o preço de mercado ou a adequabilidade para um investidor específico. Ao analisarem a solvência e a liquidez de soberanos, as agências focaram em número de fatores como risco político, estrutura econômica e de renda, perspectivas de crescimento econômico, flexibilidade fiscal, dívida pública, estabilidade de preços, flexibilidade do balanço de pagamentos e dívida e liquidez externas. O risco econômico refere-se à habilidade do governo de repagar no prazo e é uma função de fatores quantitativos e qualitativos, enquanto o risco político aponta para a determinação do soberano de repagar a dívida. Coloca-se, assim, a questão sobre a possibilidade de que as agências de classificação de risco de crédito intensifiquem ou atenuem a dinâmica de crises financeiras internacionais. Em geral, argumenta-se que, inicialmente, uma pequena saída de capital e subsequentemente uma ampliação do spread leva as agências a rebaixar a avaliação do Estado. Isso é interpretado por muitos investidores como um sinal para a retirada de capital adicional. Como resultado, o spread se torna maior, e as agências continuam a rebaixar as avaliações. Isso representa um círculo vicioso que pode dar início a uma crise financeira ao menor sinal de provocação (KRAÜSSL, 2003, p. 3-5). Entretanto, Kräussl (2003, p. 2) argumenta que um rebaixamento súbito não necessariamente intensifica uma crise financeira e pode ajudar a pôr fim à turbulência do mercado financeiro mais rapidamente. Um rebaixamento gradual de uma avaliação de crédito soberano pode intensificar uma crise financeira. Se as agências agem com precaução, um rebaixamento inicial de uma avaliação não causará uma fase de fracasso estrondoso e um aumento inicial numa avaliação não levará a uma fase de crescimento súbito.

Para Estados que contraem empréstimos, um rebaixamento na avaliação de risco de crédito por uma agência pode ter efeitos negativos no seu acesso ao crédito e no custo de se contrair um empréstimo. Assim, é razoável assumir que, diante de um rebaixamento, políticas ortodoxas que foquem na redução da inflação e dos déficits orçamentais dos governos sejam favorecidas por tais Estados. Há o risco de que, a fim de evitarem rebaixamentos nas avaliações, Estados que contraem empréstimos adotem 
políticas que atendam às preocupações de curto prazo dos investidores mesmo quando elas entram em conflito com as necessidades de desenvolvimento de longo prazo (ELKHOURY, 2009, p. 175-176). Além disso, os rebaixamentos nas avaliações de soberanos tiveram efeitos significativos de transbordamento para Estados e mercados financeiros, sendo que o sinal e a magnitude do transbordamento dependem do tipo de anúncio, do Estado que está experimentando o rebaixamento e das agências das quais os anúncios se originam. Rebaixamentos de avaliações de economias como a da Grécia tiveram efeitos de transbordamento sistemático ao longo da Zona do Euro nesta década, por exemplo. Conceitualmente, há canais potenciais pelos quais as notícias sobre avaliações de soberanos possam ter efeitos de transbordamento. Um rebaixamento das classificações de um certo Estado pode afetar a rentabilidade dos bancos em outros Estados cujos bancos mantenham sua dívida, como ocorre na Europa (AREZKI et al., 2011, p. 1-3).

A União Europeia acusou as agências de emitirem avaliações excessivamente agressivas desde o início da crise financeira internacional na década passada. Muitos membros da União Europeia continuam a culpar as agências de classificação de risco de crédito por acelerarem a crise da dívida soberana dos Estados europeus conforme tal crise se espalhou por Grécia, Irlanda e Portugal, que receberam auxílios financeiros da União Europeia e do Fundo Monetário Internacional para evitarem a inadimplência. A decisão da S\&P de rebaixar a classificação da dívida da Grécia enfraqueceu a confiança dos investidores e aprofundou a crise, tornando inevitável um pacote de ajuda financeira em maio de 2010. Os esforços dos líderes da União Europeia de negociar um segundo pacote de ajuda para a Grécia - um que contaria com a participação de credores privados - foram prejudicados pelo anúncio da S\&P em julho de 2011 de que ela provavelmente classificaria como inadimplência qualquer restruturação planejada ou voluntária da dívida grega. Em 2012, os custos de contrair empréstimos continuaram a crescer para soberanos, e houve novos receios acerca da liquidez bancária na União Europeia. Essas questões se agravaram quando a S\&P rebaixou a classificação de nove Estados da Zona do Euro, deixando a Alemanha como o único Estado na Zona do Euro a manter a avaliação mais alta - e o Estado que mais pressionava pela aplicação de medidas de austeridade nos Estados membros da Zona do Euro. Uma série de Estados europeus publicamente acusou as agências de classificação de adotarem um tratamento preferencial aos EUA, os quais, até agosto de 2011, mantiveram a avaliação mais alta apesar 
de manterem um déficit insustentável e níveis elevados de dívida pública. A União Europeia também criticou a especulação excessiva pelas agências acerca da dívida europeia, mesmo quando políticas orçamentárias concretas estavam sendo implementadas pelos Estados periféricos da Zona do Euro. Muitos europeus defenderam a criação de uma agência europeia independente de classificação de risco de crédito para responder à influência das três principais agências, mas os esforços para obter verbas para a nova agência não foram bem sucedidos (ALESSI et al., 2013).

Durante a crise financeira, a maior aversão ao risco ampliou a demanda pelo Bund alemão, que se beneficiou de seu status de "porto seguro". As avaliações de crédito específicas de cada Estado tiveram um papel importante no desenvolvimento dos spreads para Grécia, Irlanda, Portugal e Espanha. Investidores institucionais como fundos de pensão e seguradores são obrigados pela lei ou seus próprios estatutos a adquirir e manter títulos com certa avaliação mínima. As avaliações de risco de crédito são usadas por reguladores a fim de estabelecer os requisitos de capital bancário e podem impactar os portfólios dos bancos. Assim, um rebaixamento da avaliação pode gerar uma mudança de portfólio que pode afetar significativamente o rendimento das obrigações. $O$ rebaixamento das avaliações da Grécia contribuíram para desenvolvimentos nos spreads de Estados com aspectos fiscais mais fracos, como Irlanda, Portugal, Itália e Espanha. As agências de classificação de risco de crédito trouxeram o risco de contágio para o centro das discussões. Numa perspectiva de formulação de políticas, para se garantir a estabilidade do sistema financeiro na Zona do Euro, as prioridades máximas são reduzir o risco de solvência soberana e enfrentar o contágio. Os desafios que os formuladores de políticas enfrentam atualmente são reduzir gastos ineficientes e realizar reformas estruturais. No longo prazo, um desafio fundamental será fortalecer a cooperação política na Europa, possivelmente com uma instituição que garanta disciplina fiscal no longo prazo para cada membro da Zona do Euro (SANTIS, 2012, p. 3).

Em agosto de 2011, a S\&P rebaixou a classificação dos EUA pela primeira vez na história após semanas de disputas entre congressistas republicanos e democratas acerca das formas como se reduziria o déficit para se permitir um aumento do teto da dívida dos EUA. Os líderes no Congresso e a Casa Branca alcançaram um acordo para evitar a inadimplência, mas, na opinião da S\&P, não houve a implementação de medidas significativas para reduzir o déficit dos EUA ao longo dos próximos dez anos. Em 2013, 
em face do impasse sobre o teto da dívida, a Fitch colocou a avaliação dos EUA em observação negativa, citando um "jogo político de decisões temerárias" que aumentava os riscos de inadimplência pelos EUA. Críticos dessas agências nos EUA e na Europa expressaram sua preocupação de que a legislação e as regulações financeiras criaram estruturas institucionais que confiam muito pesadamente nas agências de classificação de risco de crédito, deixando aos investidores poucas alternativas. Instituiç̧ões nos EUA e na União Europeia foram criadas para a verificação da atuação dessas agências, mas é improvável que a regulação governamental possa resolver os conflitos inerentes a tais agências, em particular no que se refere à dívida soberana. Uma forma de responder ao poder monopolístico dessas agências seria parar de scolocar tanto peso nas avaliações desenvolvidas por elas (ALESSI et al., 2013).

\section{O debate sobre a regulação das agências}

Embora as agências de classificação de risco de crédito atuem desde o início do século XX, não havia regulações significativas sobre tais agências em níveis nacional e internacional até a década de 2000. Em face dos efeitos das crises para empresas e Estados, instrumentos voltados para maior regulação foram desenvolvidos nacionalmente pelos EUA e regionalmente pela União Europeia, trazendo novas regulações que, por exemplo, incluíam inspeções periódicas das operações das agências e o monitoramento das avaliações. Essas novas regulações procuram ampliar a transparência e a prestação de contas por parte das agências; porém, não parece possível que elas eliminem completamente os conflitos de interesse, ampliem a concorrência entre as agências e reduzam a venda de avaliações no curto prazo. Em nível internacional, a Organização Internacional das Comissões de Valores emitiu, em 2003, uma declaração de princípios relacionados às atividades de agências de classificação de risco de crédito e, em 2004, um código de conduta para as agências. Tais arranjos continham princípios voluntários para as agências acerca da qualidade e da integridade do processo de avaliação, da independência e da mitigação dos conflitos de interesse, das responsabilidades para emissores e da divulgação de seus próprios códigos de conduta. Em face do papel das agências na avaliação de transações financeiras estruturadas, a organização revisou o código de conduta e introduziu considerações sobre a avaliação de títulos financeiros 
estruturados; a independência das agências e a mitigação dos conflitos de interesse e as responsabilidades das agências com investidores e emissores. Entretanto, o código ainda não contém regras específicas com relação a metodologias. Em 2010, o Conselho de Estabilidade Financeira endossou princípios para se reduzir a confiança excessiva de autoridades e instituições financeiras nas avaliações de crédito. O Comitê da Basiléia de Supervisão Bancária também propôs a redução da confiança excessiva nas avaliações das agências na estrutura de capital regulatório (BAYAR, 2014, p. 53-56).

As agências de classificação de risco de crédito são vistas por especialistas e investidores como alguns dos maiores poderes não-controlados ou pouco controlados no sistema financeiro global. Nos EUA, fortaleceram-se os argumentos para uma maior regulação das agências diante das crises relacionadas à Enron e à WorldCom. As pressões por regulação que emergiram durante a atual crise financeira desembocaram em medidas introduzidas para uma maior regulação das agências. Contudo, nem sempre está claro o que a regulação das agências deve atingir. Qualquer perspectiva para regular as agências deve responder à questão do que deveria ser regulado e com quais ferramentas. A regulação somente será bem sucedida se levar em conta o que as avaliações podem ou não atingir. Uma avaliação de um instrumento financeiro oferece informação sobre a qualidade do crédito e a probabilidade de inadimplência de um ator específico ou de um produto financeiro. Porém, ela diz nada sobre o risco sistêmico, o perigo de uma reação em cadeia que resulte em dificuldades para um grande número de instituições financeiras. Enquanto parece perfeitamente racional para empresas específicas e investidores institucionais serem guiados por uma avaliação quando tomam suas decisões de investimento, essas decisões podem desestabilizar os mercados financeiros no nível sistêmico se as avaliações trazem resultados como vendas em massa e necessidade de capital adicional. O ponto principal para determinar se há risco sistêmico é consequentemente a medida em que as inadimplências individuais acontecem ao mesmo tempo. As avaliações não oferecem informações sobre esse ponto. Assim, seria um erro acreditar que a regulação das agências poderia ter mitigado prociclicidade. A regulação das agências também pode fazer nada para solucionar os problemas causados pelo uso de avaliações para propósitos regulatórios (UTZIG, 2010, p. 4-5).

Os objetivos de regular as agências de classificação de risco de crédito podem somente ser a ampliação da confiabilidade das avaliações e a mitigação de conflitos 
de interesse. Para que se atinjam tais objetivos, há consenso em torno do não-monitoramento das metodologias de avaliação. Isso se justifica não só por razões de concorrência, mas porque a regulação desse tipo pode resultar na consideração do Estado como parcialmente responsável pelas avaliações divulgadas. Ademais, sendo os Estados também emissores de dívidas, um novo conflito de interesses nasceria se os Estados estivessem em uma posição em que influenciassem as metodologias utilizadas para se avaliarem títulos soberanos. A extensão de métodos possíveis de regulação é grande. Em uma das pontas do espectro está a ideia de que as agências deveriam se autorregular; na outra, estão as demandas para que o processo de avaliação seja confiado ao setor público, o que, em geral, é descartado porque o Estado teria que assumir responsabilidade pelas avaliações. Entre a autorregulação e a criação de agências estatais, está o modelo de agências do setor privado reguladas pelo Estado (UTZIG, p. 5-6).

Cabe avaliar mais precisamente os métodos de regulação. O sucesso de qualquer regime de autorregulação depende da questão do controle. É necessário que haja supervisão efetiva para se trazerem à tona os desvios de regras autoimpostas. Além disso, deve haver um mecanismo para a aplicação de sanções. Uma ferramenta evidente de supervisão é a própria qualidade da avaliação, que pode ser facilmente monitorada pelos participantes do mercado e pela mídia. Os investidores, por sua vez, somente aceitarão avaliações confiáveis no longo prazo. Para os defensores da regulação estatal, uma lição fundamental a ser aprendida da crise atual é que é vital para as avaliações serem capazes de oferecer uma indicação confiável da fiabilidade creditícia de um devedor mesmo em tempos de crise. Nessa perspectiva, a crise atual prova que não se pode sempre confiar na regra autodisciplinadora assumida pela reputação e que tal regra somente funciona no longo prazo. A autorregulação não funciona efetivamente quando a pressão da reputação como um poder controlador existe somente a um nível limitado devido à falta de concorrência. Não se pode esquecer que as avaliações também regulam o acesso ao mercado. Ademais, as agências não demonstraram que sejam totalmente capazes, sob o regime existente, de resolver conflitos de interesse de forma bem sucedida. Tendo em vista o interesse na estabilidade do mercado financeiro, especialistas acreditam que as falhas atuais no mercado justificariam a regulação estatal (UTZIG, 2010, p. 5-6). 
As respostas regulatórias são compreensíveis em face dos erros cometidos pelas agências, mas elas não necessariamente alteram as regras que levaram os julgamentos das agências para o centro do processo informacional sobre títulos. Os esforços regulatórios para solucionar problemas, ao prescreverem estruturas e processos específicos, inevitavelmente restringem a flexibilidade, ampliam os custos e desencorajam novas entradas e a inovação no desenvolvimento e na análise da informação para o julgamento da fiabilidade creditícia dos títulos. Embora os esforços para a ampliação da transparência das agências possam ajudar a reduzir os problemas relacionados à assimetria de informação, elas também têm o potencial de erodir a propriedade intelectual de uma agência e, no longo prazo, desencorajar a criação de propriedade intelectual futura (WHITE, 2010a, p. 223).

\section{Considerações finais}

As agências de classificação de risco de crédito surgiram nos EUA na primeira década do século XX e se tornaram uma parte importante do sistema financeiro global num contexto de globalização dos mercados financeiros em meados da década de 1970. As falências de empresas com a Enron e a WorldCom e as crises como a asiática em 1997, a crise financeira global iniciada em 2008 e a crise da dívida soberana da Zona do Euro levaram investidores e autoridades públicas a investigar a precisão e a confiabilidade das avaliações de risco de crédito (BAYAR, 2014, p. 49). O encontro dos líderes do G20 em 2009, no ápice da crise financeira iniciada em 2008, reiterou a necessidade de regras e procedimentos claros para impedir conflitos de interesse, garantir transparência e qualidade no processo de avaliação e requerer registro mandatório das agências de classificação de risco de crédito. Os líderes sugeriram a colaboração para garantir a aplicação uniforme dos princípios. De maneira geral, lideranças políticas e analistas apontam frequentemente o impacto sistêmico das avaliações. Porém, deve-se destacar que outros jogadores também têm responsabilidade pelos acontecimentos recentes nos mercados. Investidores institucionais negligenciaram a gestão de risco e medidas internas de controle que deveriam ter requerido um melhor monitoramento dos riscos associados a investimentos em produtos estruturados. Os reguladores fracassaram ao identificar o 
rápido crescimento no risco sistêmico latente conforme tais títulos se proliferavam por todo o sistema financeiro e além das fronteiras nacionais (RANDHAWA, 2011, p. 11-13).

O papel central que as agências de classificação de risco de crédito tiveram na crise financeira iniciada em 2008 levou à ampliação da regulação de tais agências e de apelos políticos para ainda mais regulação. Porém, os defensores dessa posição ignoram o espaço central das agências na produção de informações sobre a fiabilidade creditícia e os perigos de que mais regulação erga mais barreiras à entrada e à inovação na oferta de informação. Um caminho melhor poderia ser a redução da regulação das agências concomitantemente à reforma da regulação dos portfólios de títulos das instituições financeiras ao se eliminar a confiança regulatória nas avaliações. Isso permitiria às instituições financeiras obterem as informações sobre fiabilidade creditícia a partir de uma extensão maior de fontes, o que encorajaria novas metodologias, tecnologias, procedimentos e modelos de negócios (WHITE, 2010b).

\section{Referências bibliográficas:}

ALESSI, C.; WOLVERSON, R.; SERGIE, M.A. The credit rating controversy. CFR website, out. 2013. Disponível em: <http://www.cfr.org/financial-crises/credit-rating-controversy/ p22328>. Acesso em: 18 abr. 2014.

AREZKI, R.; CANDELON, B; SY, A.N.R. Sovereign Rating News and Financial Markets Spillovers: Evidence from the European Debt Crisis. IMF Working Paper, WP/11/68, p.1-26, mar. 2011.

BAYAR, Y. Recent Financial Crises and Regulations on the Credit Rating Agencies. Research in World Economy, v. 5, n. 1, p. 49-58, 2014.

BOLTON, P.; FREIXAS, X.; SHAPIRO, J. The Credit Ratings Game. The Journal of Finance, v. LXVII, n. 1, p. 85-111, fev. 2012.

ELKHOURY, M. Credit rating agencies and their potential impact on developing countries. In: UNITED NATIONS CONFERENCE ON TRADE AND DEVELOPMENT. Compendium on debt sustainability and development. Nova York, Genebra: United Nations, 2009, p. 165-189.

FERRI, G.; LIU, L.-G.; STIGLITZ, J.E. The Procyclical Role of Rating Agencies: Evidence from the East Asian Crisis. Economic Notes, v. 28, n. 3, p. 335-355, 1999. 
HUNT, J.P. Credit rating agencies and the "worldwide credit crisis": the limits of reputation, the insufficiency of reform, and a proposal for improvement. Selected works, p. 1-75, jan. 2009. Disponível em: <http://works.bepress.com/john_hunt/1>. Acesso em: 19 abr. 2014.

KATZ, J.; SALINAS, E.; STEPHANOU, C. Credit Rating Agencies. Crisis Response: Public Policy for the Private Sector, n. 8, p. 1-8, out. 2009.

KERWER, D. Standardizing as governance: the case of credit rating agencies. In: HÉRITIER, A. (Ed.) Common Goods: Reinventing European Integration Governance. Lanham: Rowmann \& Littlefield, 2002, p. 293-316.

KRÄUSSL, R. Sovereign Credit Ratings and Their Impact on Recent Financial Crises, 2003, p. $1-23$.

RANDHAWA, D.S. The past, present, and a possible future direction for the credit rating industry. Global Credit Review, v. 1, n. 1, p. 1-14, 2011.

SANTIS, R.A. The euro area sovereign debt crisis: safe haven, credit rating agencies and the spread of the fever from Greece, Ireland and Portugal. European Central Bank Working Paper Series, n. 1419, p. 1-59, fev. 2012.

UTZIG, S. The Financial Crisis and the Regulation of Credit Rating Agencies: A European Banking Perspective. ADBI Working Paper Series, n. 188, p. 1-22, jan. 2010.

WHITE, L.J. Markets: the Credit Rating Agencies. Journal of Economic Perspectives, v. 24, n. 2, p. 211-226, 2010a.

WHITE, L.J. Credit-Rating Agencies and the Financial Crisis: Less Regulation of CRAs is a Better Response. Journal of International Banking Law and Regulation, v. 25, n. 4, p. 170-179, 2010b. 